\title{
A AVALIAÇÃO AMBIENTAL INTEGRADA E OS CENÁRIOS SOCIOECONÔMICOS DE MUNICÍPIOS IMPACTADOS PELAS USINAS HIDRELÉTRICAS PEIXE ANGICAL E SÃO SALVADOR NO RIO TOCANTINS
}

INTEGRATIVE ENVIRONMENTAL ASSESSMENT AND THE SOCIOECONOMICS SCENARIOS OF MUNICIPALITIES IMPACTED BY THE HYDROELETRIC POWER PLANTS PEIXE ANGICAL AND SAO SALVADOR IN TOCANTINS RIVER, BRAZIL

\section{Kiara Lubick}

Silva Maldaner (10)

Doutoranda em Ciências do Ambiente, Programa de Pós Graduação em Ciências do Ambiente, Universidade Federal do Tocantins - Palmas (TO), Brasil.

\section{Adila Maria}

Taveira de Lima

Doutoranda em Ciências do Ambiente, Programa de Pós-Graduação em Ciências do Ambiente, Universidade Federal do Tocantins - Palmas (TO), Brasil.

\section{Alberto Akama}

Pesquisador no Museu Paraense Emílio Goeldi. Professor do Programa de Pós-Graduação em Ciências do Ambiente, Universidade Federal do Tocantins - Palmas (TO), Brasil.

\section{Elineide Eugênio}

\section{Marques (1)}

Doutora em Ecologia de Ambientes Aquáticos. Professora do Programa de Pós-Graduação em Ciências do Ambiente, Universidade Federal do Tocantins - Palmas (TO), Brasil.

\section{Endereço para correspondência:}

Adila Maria Taveira de Lima-

Quadra 605 sul, alameda 16 Q 21

casa 20 - Plano Diretor Sul -

CEP: 77016-456-Palmas (TO), BrasilE-mail:adm.adila@gmail.com

Recebido em: 12/06/2019

Aceito em: 03/10/2019

\section{RESUMO}

Este estudo comparativo buscou analisar se as previsões da Avaliação Ambiental Integrada (AAI) dos Aproveitamentos Hidrelétricos da Bacia do Rio Tocantins foram concretizadas a médio prazo, no período compreendido entre 2006 e 2015. Foram considerados os cenários de potencialidades no que se refere à socioeconomia dos municípios de Palmeirópolis, Paranã, Peixe e São Salvador do Tocantins, no estado do Tocantins, Brasil, impactados diretamente pelas usinas hidrelétricas (UHEs) Peixe Angical e São Salvador. Como metodologia, foi utilizada a análise de conteúdo da AAl e a análise dos dados socioeconômicos dos municípios investigados. Os resultados apontam que os cenários socioeconômicos previstos foram parcialmente alcançados, especialmente comoaumento da receita municipal. Porém, outros indicadores socioeconômicos revelaram índice de desenvolvimento econômico e social nos municípios não correspondente às previsões contempladas no estudo de planejamento da bacia.

Palavras-chave: desenvolvimento; municípios tocantinenses; indicadores; impactos.

\section{ABSTRACT}

This comparative study tried to analyze whether the predictions of the Integrated Environmental Assessment (IEA) of the Tocantins River Basin Hydroelectric Plants were realized in the medium term, from 2006 to 2015. Were considered the potential scenarios regarding the socioeconomics of the municipalities of Palmeirópolis, Paranã, Peixe and São Salvador do Tocantins, Tocantins State, Brazil, directly impacted by the Peixe Angical and São Salvador Hydroelectric Power Plants (HPP). As methodology was used the content analysis of IEA and analysis of socioeconomic data of the municipalities investigated. The results indicate that the predicted socioeconomic scenarios were partially achieved, especially with the increase in municipal revenue. However, other socioeconomic indicators revealed an index of economic and social development in the municipalities not corresponding to the forecasts contemplated in the basin planning study.

Keywords: Development; Tocantins municipalities; indicators; impacts 


\section{INTRODUÇÃO}

Ao longo da história, os grandes projetos de desenvolvimento têm moldado a estratégia política para o progresso socioeconômico do Brasil, constituindo-se em mecanismos destinados ao aprimoramento da infraestrutura básica, à geração de empregos e à sustentação da economia. Esses projetos materializam-se em diferentes obras planejadas, a exemplo da construção de usinas hidrelétricas (UHEs) para potencializar a produção de energia, a exploração de minérios com vistas à competitividade e à exportação e a ampliação dos eixos de transporte, além da intensificação agrícola. Esses projetos são, ainda, propagados como uma forma de promover o desenvolvimento local, a melhoria da qualidade de vida, a redução da pobreza e das desigualdades sociais.

Vistos sob essa perspectiva, os grandes projetos desenvolvimentistas se mostram como soluções para décadas de subdesenvolvimento. Entretanto, um olhar mais crítico às suas entrelinhas revela interesses governamentais e de grupos empresariais na contramão de um modelo de desenvolvimento sustentável e inclusivo que, de fato, atenda às expectativas de justiça social e ambiental (LITTLE, 2014). Especialmente no que diz respeito à construção de hidrelétricas, os interesses de empreiteiras apoiam a manutenção do modelo de grandes barragens no Brasil, sob a justificativa da ideia de energia limpa (FAINGUELERNT, 2016).

A influência do mercado é observada desde a elaboração das análises técnicas, que servem de base para a aprovação e a implementação dos empreendimentos, até a fase de execução e operação do projeto. A tendência dos estudos de impacto socioambiental é de exaltar aspectos positivos da obra em termos de desenvolvimento local e regional, ao passo que as intervenções negativas são minimizadas, às vezes justificadas ou, em alguns casos, desconsideradas em prol de uma causa de interesse nacional e, portanto, necessária, mesmo causando impactos irremediáveis.

Essa situação é particularmente frequente no processo de construção de UHEs, cuja etapa de planejamento envolve, como uma de suas fases principais, a produção da Avaliação Ambiental Integrada (AAI) das principais bacias hidrográficas brasileiras (EPE, 2007). Esse trabaIho compreende a identificação dos impactos a partir do conjunto de ações que interagem na bacia, tipificando os efeitos sinérgicos e cumulativos dos empreendi- mentos na fase de produção do documento e dos previstos para o futuro (TUCCl; MENDES, 2006; EPE, 2007).

Nesse documento, são ordenados e classificados os impactos positivos e os negativos. No entanto, por mais preocupantes que se revelem esses últimos em termos de fragilidades e prejuízos ao ambiente, aos ecossistemas e às populações humanas, a perspectiva da AAl é de estudo e planejamento da bacia para a implantação de hidrelétricas, propagando as potencialidades das usinas para a indução do desenvolvimento socioeconômico das localidades e regiões onde são implantadas, minimizando os impactos negativos.

Cenários otimistas são simulados a curto, médio e longo prazos, projetando o número de postos de trabalho a serem criados, a dinamização da economia e as obras que serão realizadas para a melhoria da infraestrutura dos municípios, entre outros benefícios que resultam em bem-estar econômico e social, principalmente da localidade onde a obra está inserida. Expectativas essas que nem sempre se traduzem em realidade, já que, ao contrário das previsões otimistas, a construção de hidrelétricas pode deixar um rastro de impactos negativos, causando desestruturação de atividades preexistentes, crescimento populacional desordenado e degradação ambiental (BORTOLETO, 2001).

Para fins desta pesquisa, buscou-se analisar a AAI dos Aproveitamentos Hidrelétricos da Bacia do Rio Tocantins, localizada entre as regiões Centro-Oeste e Norte do Brasil e que nas últimas décadas foi intensamente explorada sob a justificativa de contribuir com o fornecimento de energia elétrica para a industrialização do país e com o desenvolvimento de áreas ainda carentes de intervenção pública. Com foco em um compartimento específico da bacia, o objetivo da pesquisa foi analisar se os cenários de potencialidades a médio prazo, compreendendo o período de 2006 a 2015, previstos na $\mathrm{AAl}$, foram concretizados no que se refere à socioeconomia dos municípios de Palmeirópolis, Paranã, Peixe e São Salvador do Tocantins, no estado do Tocantins, impactados diretamente pelas UHEs de Peixe Angical e São Salvador, localizadas na sub-bacia 21 da AAl da Bacia do Rio Tocantins.

Ressalta-se que na época da produção dos estudos técnicos e da aprovação para a implantação dos em- 
preendimentos, essas obras foram propagadas como soluções para reverter o atraso econômico e social que se perpetuava na região do antigo norte goiano, desmembrado, em 1988, para a criação do estado do Tocantins (BRASIL, 2008a). O trabalho, assim, tem sua relevância por analisar qual a real contribuição das UHEs sobre o desenvolvimento socioeconômico local a partir da identificação e da avaliação dos prognósticos previstos na AAI. Acrescenta-se ainda a contribuição para os estudos de impacto ambiental dos empreendimentos hidrelétricos no panorama brasileiro.

\section{APORTE TEÓRICO}

O discurso constante nos estudos de viabilidade técnica das UHEs defende a ideia desses empreendimentos como promovedores de desenvolvimento econômico e social dos municípios e das regiões de suas sedes, visto à grandeza dos projetos, capazes de movimentar uma grande soma de recursos financeiros. Esses projetos são apresentados à sociedade como estratégia para otimização da economia com contribuição para a redução das desigualdades inter-regionais (BORTOLETO, 2001). Os empreendimentos hidrelétricos integram o grupo dos chamados Projetos de Grande Escala (PGE), que se caracterizam, como ressalta Rocha (2016), pelo gigantismo que, além da dimensão física, implica em enorme demanda de capital e trabalho. "O gigantismo supõe que os PGE promovam naturalmente o desenvolvimento dos locais onde venham a se inserir, especialmente na fase em que os trabalhos de instalação são mais agudos" (ROCHA, 2016, p. 16).

No entanto, Castro, Hogenboom e Baud (2015) destacam que esse processo afeta grande número de grupos sociais em todos os países latino-americanos, principalmente nas áreas rurais. Além disso, há inúmeras tensões socioambientais que agravam os problemas econômicos e a injustiça social de longa data.

Bortoleto (2001) considera que o desenvolvimento advindo dos PGEs se restringe à escala nacional, não favorecendo a região onde o empreendimento é instalado. Para Vainer e Araújo (1992, p. 34), "o sempre anunciado 'progresso' para a região e a modernidade estampada em processos coloridos raramente ultrapassam os limites do próprio empreendimento - e das vilas para engenheiros e técnicos de nível superior", recriando os tradicionais enclaves coloniais. $\mathrm{O}$ saldo em termos de expansão da economia acaba por ser altamente negativo para as comunidades locais.

Essa situação é recorrente na implantação dos projetos hidrelétricos visto a amplitude de impactos socioambientais e seus efeitos sobre as condições de sobrevi- vência das populações afetadas, uma vez que estas perdem seus recursos vitais de sobrevivência (FEARNSIDE, 2015; AMNESTY INTERNATIONAL, 2016).

Além disso, o desenvolvimento local prometido por meio da oferta de emprego propagada durante a implementação desses empreendimentos não passaria de ilusão, já que, ao contrário do discurso proclamado por governo e empresários, o que se origina, na verdade, é uma concentração de desempregados. Isso porque as oportunidades de trabalho geradas no período de implantação das usinas geralmente são inferiores ao número de pessoas que se aglomeram em busca de trabalho, em razão do afluxo migratório (VAINER; ARAÚJO, 1992). "No momento em que se concluem as obras e se desmobiliza a maior parte do contingente de mão de obra - particularmente, a não qualificada - a região se transforma num grande bolsão de desemprego" (VAINER; ARAÚJO, 1992, p. 36).

Ressalta-se ainda que os municípios impactados por hidrelétricas, mesmo com o aumento de suas receitas, não são capazes de suprir as demandas, cada vez mais crescentes, de saneamento básico, habitação, educação, atendimento em saúde e outros serviços essenciais. Soma-se a esses problemas a falta de garantias de que o dinheiro derivado de pagamentos de salários aos trabalhadores irá circular no âmbito local, impulsionando a economia dos municípios e das regiões. Gomes et al. (2017) explicam que os recursos financeiros "ficam dispersos em uma grande área geográfica ao redor do empreendimento, sendo menos concentrados localmente do que normalmente se estima" (GOMES et al., 2017, p. 154). As migrações dos operários entre um empreendimento e outro também contribuiriam para afastar o dinheiro da localidade.

Saifi e Dagnino (2011, p. 2) apontam que "os grandes projetos de investimentos econômicos não devem e nem podem ser confundidos com um projeto de desenvolvimento, seja ele local, regional e/ou nacional", 
uma vez que o desenvolvimento precisa estar integrado, além da expansão da base material, à redução da pobreza, do desemprego e da desigualdade. "Se a situação é inversa, se estes problemas se agravaram, independentemente do que se tenha produzido - por exemplo, um incremento no [produto interno bruto] PIB per capita - seria um equívoco falar em desenvolvimento" (SAIFI; DAGNINO, 2011, p. 2).

No caso específico das UHEs, Benincá (2011) ressalta que os efeitos das barragens sobre a vida das pessoas quase nunca são devidamente mensurados e reparados. É comum observar que aquelas que foram reassentadas raramente tiveram seus meios de subsistência restaurados, tendo em vista que os programas de deslocamento e reassentamento das pessoas em geral priorizam a mudança física, ignorando a recuperação econômica e social dos deslocados. Além disso, os prejuízos ambientais são irreversíveis, com casos de mortandade de peixes, extinção de espécies, migração de animais silvestres, entre vários outros problemas. Esses fatores tornam-se praticamente impossíveis de quantificar e qualificar diante da totalidade dos impactos que incidem sobre as pessoas e o conjunto da biodiversidade.
Rocha e Pase (2015), por sua vez, acrescentam que a instalação de uma UHE promove a reconfiguração geográfica e social local com duas lógicas distintas e conflitantes de apropriação. A primeira é a dos atingidos, dos agricultores familiares, que lutam pela permanência de seus espaços de origem. A segunda é baseada na visão desenvolvimentista, porém sem a intenção de melhorar as conjunturas locais.

Little (2014) acrescenta que os estudos de viabilidade técnica dos projetos hidrelétricos privilegiam os aspectos econômicos em detrimento aos impactos sociais e ambientais. Os efeitos resultantes, principalmente no final da fase de construção e início da operação dos empreendimentos, seriam, assim, de acordo com Gomes et al. (2017, p. 154), potencialmente "desestabilizadores nos cenários do desenvolvimento municipal". Diante disso, é comum observar que, após a obra construída, constantemente sobram, para os municípios, problemas sociais, ambientais e econômicos, reclamações e processos judiciais e, ainda, medidas mitigadoras não concluídas. A oscilação econômica ocasionada pelo empreendimento ocorre em curto espaço de tempo. Esse fator pode comprometer também a governança do município.

\section{A Avaliação Ambiental Integrada da Bacia Hidrográfica do Rio Tocantins}

A partir do ano de 2003, o Instituto Brasileiro de Meio Ambiente e Recursos Naturais Renováveis (IBAMA) ampliou a lista de estudos técnicos exigidos para o licenciamento ambiental de UHEs. Atendendo à Resolução do Conselho Nacional do Meio Ambiente (CONAMA) no 01/86 (BRASIL, 1986), além do Estudo de Impacto Ambiental (EIA) específico, e com profundidade limitada, de empreendimentos individualizados, passou-se a adotar também a AAI da bacia hidrográfica. Esse instrumento de avaliação diferencia-se do EIA por seu escopo mais amplo, que permite a identificação dos efeitos sinérgicos, cumulativos e integrados de toda a bacia considerando os empreendimentos atuais e previstos a médio e longo prazos (TUCCl; MENDES, 2006; EPE, 2007). Isso torna possível a análise antecipada e integrada das políticas, dos planos e dos programas que interferem no ambiente de uma determinada bacia hidrográfica.

A AAl é entendida como "a identificação dos impactos a partir do conjunto de ações que interagem na bacia e se refletem no seu próprio espaço" (TUCCI; MENDES, 2006, p. 239). Seu caráter interdisciplinar permite avaliar os impactos a partir de três dimensões - meio socioeconômico, ambiente terrestre e ambiente aquático - , visando compatibilizar a produção de energia elétrica com a conservação da biodiversidade, com a manutenção da sobrevivência das populações humanas locais e com a tendência de desenvolvimento socioeconômico da região da bacia (TUCCl; MENDES, 2006).

Ainda que se proponha ao planejamento da bacia, a AAl deixa margem para críticas pela forma como é produzida. Piagentini e Favareto (2014) destacam o desconhecimento e a controvérsia que ainda pairam sobre as dimensões, em termos de extensão de alcance, de alguns dos impactos provocados por grandes projetos hidrelétricos, o que dificulta a avaliação dos efeitos dos impactos. Essa dificuldade em avaliar os impactos é observada em alguns pontos da AAI dos Aproveitamentos Hidrelétricos da Bacia do Rio Tocantins.

É o que se percebe no aspecto dimensão social, no qual se analisou apenas o Índice de Desenvolvimento 
Humano Municipal (IDH-M), contemplando somente os componentes educação, saúde e renda (EPE, 2007), deixando de confrontar os dados com outras metodologias que promovem uma análise mais ampla dos indicativos das necessidades básicas humanas e da qualidade de vida da população.

Em outro ponto controverso, mesmo identificando tanto as potencialidades quanto as fragilidades em termos de socioeconomia, a postura do trabalho é de enaltecer os impactos positivos advindos da implantação de uma UHE e sua capacidade de "acentuar o fortalecimento econômico e o dinamismo demográfico nas regiões sob suas influências" (EPE, 2007, p. 92), com reflexos, conforme o documento, na melhoria das condições de vida da população e na promoção de inclusão social. Tais vantagens são intensamente propagadas, especialmente no que se refere à criação de postos de trabaIho, sobre a qual a AAI destaca:

Em termos dos impactos positivos, é bastante significativa a geração de empregos diretos (durante a obra) e indiretos e de efeito renda (resultantes da animação econômica gerada pela implantação das usinas), em decorrência do porte considerável das usinas e de seu potencial de geração (EPE, 2007, p. 193).

No entanto, essas previsões podem não se concretizar ao longo do tempo, sobretudo no período do pós-barragem.

Com a adoção da AAl, e de modo a atender o crescimento da demanda energética no país, esses estudos integrados foram mais incentivados pelos órgãos governamentais. Westin, Santos e Martins (2014) ressaltam que 14 AAls foram elaboradas para as bacias hidrográficas brasileiras, contemplando especialmente a região amazônica, que a partir do ano 2000 teve seu potencial energético mais intensificado, promovendo conflitos ambientais e sociais. Entre os estudos, está a AAl dos Aproveitamentos Hidrelétricos da Bacia do Rio Tocantins, elaborada pela Empresa de Pesquisa
Energética (EPE) a partir de 2004 e publicada em 2007. $O$ documento foi produzido em quatro etapas: caracterização da bacia; avaliação ambiental distribuída e conflitos; avaliação ambiental integrada e diretrizes; e relatório final. O conjunto dessas etapas trouxe como resultados: aspectos ambientais principais; caracterização das variáveis e indicadores para avaliação integrada dos impactos; análise integrada de impactos nas cenas atual, de médio prazo e longo prazo; síntese integrada da avaliação dessas transformações no contexto dos processos maiores de evolução da bacia, dando suporte às principais conclusões; e, finalmente, as diretrizes e as recomendações. $O$ estudo identificou potencialidades para o desenvolvimento da região nos cenários a curto (2006), médio (2015) e longo prazos (2025), atribuindo as seguintes classificações: alta, moderadamente alta, média, moderadamente baixa e baixa (EPE, 2007).

Esse tipo de trabalho técnico aplicado às principais bacias hidrográficas brasileiras é entendido pelo governo como um importante instrumento de planejamento do setor elétrico, inovando ao passar de seus estudos de mercado abrangentes para um enfoque espacializado. No caso da bacia hidrográfica do rio Tocantins, a AAI torna-se mais relevante dada a sua extensão, à complexidade de sua ambiência, ao volume de recursos hídricos e ao papel que pode cumprir no suprimento de energia elétrica no contexto do planejamento energético brasileiro (EPE, 2007).

Ademais, o rio Tocantins já possui sete UHEs em operação, com planejamento para instalação de mais três, sem contar as Pequenas Centrais Hidrelétricas (PCH) distribuídas ao longo da bacia hidrográfica. Os cenários a curto, médio e longo prazos previstos na AAl são parâmetros para avaliações do que foi planejado e implementado e suas implicações sobre o desenvolvimento dos municípios impactados pelos empreendimentos.

\section{ASPECTOS METODOLÓGICOS}

Este estudo comparativo analisou os cenários de potencialidades da AAI dos Aproveitamentos Hidrelétricos da Bacia do Rio Tocantins previstos para o compartimento 2, sub-bacia 21, a médio prazo (2006 até 2015), comparando-os com os dados socioeconômicos das localidades investigadas. $O$ recorte da área abrange os municípios do território do estado do Tocantins: Pal- meirópolis, Paranã, Peixe e São Salvador do Tocantins, impactados pelas UHEs Peixe Angical e São Salvador.

A metodologia utilizada foi a análise de conteúdo da AAl e a análise dos dados socioeconômicos dos quatro municípios diretamente impactados pelos empreendimentos. A análise de conteúdo é definida como um 
"conjunto de técnicas de análises de comunicação" (BARDIN, 2011, p. 37) que pode ser aplicado a discursos diversificados. Duas funções distintas são atribuídas a esse método: a primeira é a função heurística, que enriquece a tentativa exploratória, aumentando a propensão para a descoberta. Seria a análise "para ver o que dá" (BARDIN, 2011, p. 335). Já a segunda é a função de "administração da prova", na qual hipóteses sob a forma de questões ou afirmações servem de diretrizes para a análise, a fim de confirmar uma informação. As duas funções interagem, reforçando uma à outra (BARDIN, 2011). Esse método permitiu identificar as potencialidades da AAI dos Aproveitamentos Hidrelétricos da Bacia do Rio Tocantins para a região foco do estudo. A AAI foi produzida pela EPE em 2007, estando disponível para acesso público no portal da instituição.

\section{Caracterização da área da pesquisa}

A extensão territorial de Palmeirópolis é de $1.703 .936 \mathrm{~km}^{2}$. O município de Paranã possui área territorial de $1.120,216 \mathrm{~km}^{2}$, enquanto São Salvador do Tocantins tem $1.422,033 \mathrm{~km}^{2}$ e Peixe, $5.291,206 \mathrm{~km}^{2}$. Localizados na Região Sudeste do estado do Tocantins, no Brasil, os municípios contam com infraestrutura básica, com água encanada, pavimentação das principais ruas e avenidas, hospitais municipais para atendimentos de baixa complexidade e unidades básicas de saúde (GOVERNO DO TOCANTINS, 2012). A estrutura educacional é composta de creches municipais e escolas municipais e estaduais. $O$ ensino superior depende de instituições de municípios-polos do sudeste tocantinense, a exemplo das cidades de Arraias e Gurupi, que são os principais centros urbanos da região.

Esses quatro municípios foram impactados pela implantação de UHEs construídas ao longo do curso
Para comparar as previsões da AAl com a realidade dos municípios, foram analisados os dados socioeconômicos das localidades como forma de averiguar as condições de desenvolvimento entre os anos de 2005 e 2015. Foram analisadas as seguintes informações: população, saldo de empregos, empresas criadas, PIB, Imposto sobre Circulação de Mercadoria e Serviços (ICMS), Índice de Desenvolvimento Humano (IDH), taxa de analfabetismo, renda e mortalidade infantil.

Os dados foram informados pelas instituições: Instituto Brasileiro de Geografia e Estatística (IBGE), Departamento de Informática do Sistema Único de Saúde (DATASUS), Secretaria da Fazenda e Planejamento do Estado do Tocantins (SEPLAN), Ministério do Trabalho e Emprego (MTE) e Serviço Brasileiro de Apoio às Micro e Pequenas Empresas (Sebrae).

do rio Tocantins. A UHE Peixe Angical começou a ser construída em 2002 e teve suas operações iniciadas em 2006, com capacidade de geração de $452 \mathrm{MW}$ de energia elétrica. Está localizada entre os municípios de Peixe, São Salvador do Tocantins e Paranã, impactando diretamente esses três municípios (Figura 1). A implementação dessa hidrelétrica formou um reservatório de $294 \mathrm{~km}^{2}$. A UHE São Salvador tem capacidade instalada de $243 \mathrm{MW}$, e fica localizada entre os municípios de São Salvador do Tocantins e Paranã (BRASIL, 2015). Essa usina teve a construção iniciada em 2005 e começou a operar em 2008, com área de $104 \mathrm{~km}^{2}$ de reservatório, impactando diretamente, no estado do Tocantins, os municípios de Paranã, São Salvador do Tocantins e Palmeirópolis (Figura 1). Os municípios de Paranã e São Salvador do Tocantins sofreram implicações das duas UHEs.

\section{RESULTADOS E DISCUSSÃO}

A AAI dos Aproveitamentos Hidrelétricos da Bacia do Rio Tocantins classifica como potencialidade a capacidade de transformação dos recursos socioeconômicos da bacia em novos capitais físicos, produtivos e humanos resultantes dos aproveitamentos hidrelétricos, em cenários a curto (2006), médio (2015) e longo prazos (2025). O capítulo específico da socioeconomia identifica subáreas fundamentais, pautadas nos Indicadores Municipais de Sustentabilidade, que refletem o desem- penho econômico, o comportamento populacional e as condições de vida da população, agrupados em três dimensões: econômica, demográfica e social (EPE, 2007).

A área de localização dos municípios investigados (subárea 2) é caracterizada no documento pela "predominância de municípios de baixa sustentabilidade econômica, com padrão produtivo precário, evolução demográfica declinante combinada às piores condi- 
ções de vida da população, baixa pressão antrópica e qualidade institucional fraca" (EPE, 2007, p. 151). A AAl, entretanto, preconiza que a implementação de hidrelétricas contribuirá para reverter essas deficiências locais, visto a identificação de potencialidades que serão geradas, entre as quais a geração de emprego, a dinamização da economia por meio de oferta de produtos e serviços, além da possibilidade de maior aporte de recursos financeiros aos municípios em virtude do aumento da arrecadação de impostos. Partindo dessa

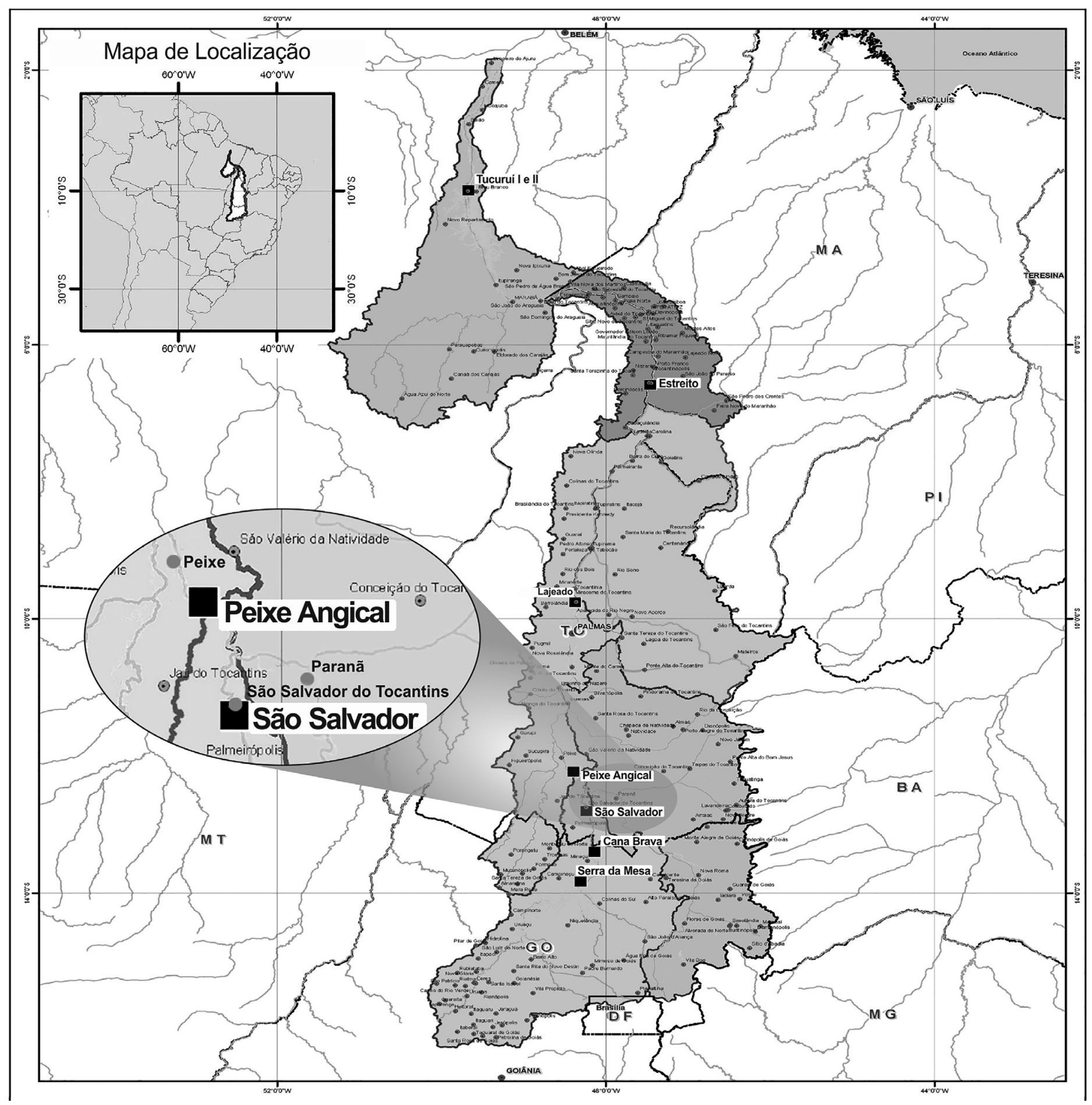

Fonte: adaptado de EPE (2007).

Figura 1 - Mapa com a localização das usinas hidrelétricas Peixe Angical e São Salvador e municípios pesquisados. 
perspectiva, a AAI do Rio Tocantins traçou previsões socioeconômicas para os municípios das áreas de abrangências da UHE Peixe Angical e da UHE São Salvador. Os Quadros 1 e 2 apresentam os cenários previstos a curto (até 2006) e médio prazos (até 2015) estudados neste trabalho.

Observa-se, a partir da análise dos cenários, uma previsão bastante otimista de que as UHEs venham a contribuir com os municípios. A AAI destaca a "magnitude moderadamente alta" (EPE, 2007, p. 198) referente à criação de postos de trabalho decorrente da animação econômica e do aumento da arrecadação municipal associado às UHEs (EPE, 2007). O valor adicionado foi elaborado apoiado na hipótese de que deveria haver o impulsionamento de atividades produtivas ao longo da bacia, tais como o plantio de soja e açúcar, a minera- ção, bem como o próprio serviço de geração de energia hidrelétrica que reflete o aumento do valor adicionado, "quer seja pela própria geração, quer seja pelas possibilidades de desenvolvimento de outras atividades intensivas em energia elétrica" (EPE, 2007, p. 184).

Passados dez anos da elaboração da AAl, os dados socioeconômicos, no entanto, revelam realidades conflitantes com as previsões socioeconômicas para as localidades investigadas. Em termos de população, observaram-se variações entre os municípios, conforme apresenta a Tabela 1.

Paranã demonstra um movimento de aumento populacional, principalmente nos períodos de 2007 a 2009, chegando em 2009 com um acréscimo de 815 habitantes em relação a 2006. Esse período coincide com

Quadro 1 - Classificação final dos impactos positivos: cenário 2006.

\begin{tabular}{|l|c|c|c|}
\hline Impacto positivo & \multicolumn{1}{|c|}{$\begin{array}{c}\text { Classificação } \\
\text { do impacto }\end{array}$} & $\begin{array}{l}\text { Classificação da } \\
\text { potencialidade }\end{array}$ & $\begin{array}{c}\text { Classificação } \\
\text { final do impacto }\end{array}$ \\
\hline $\begin{array}{l}\text { Criação de oportunidade de trabalho } \\
\text { derivada da animação econômica }\end{array}$ & Moderadamente alto & Alto & Moderadamente alto \\
\hline $\begin{array}{l}\text { Criação de oportunidade de trabalho } \\
\text { durante a construção das UHEs }\end{array}$ & Baixo & Alto & Médio \\
\hline $\begin{array}{l}\text { Aumento da arrecadação municipal } \\
\text { Expansão do valor adicionado }\end{array}$ & Sem informação & Alto & Moderadamente alto \\
\hline
\end{tabular}

UHEs: usinas hidrelétricas.

Fonte: adaptado de EPE (2007).

Quadro 2 - Classificação final dos impactos positivos: cenário 2015.

\begin{tabular}{|l|c|c|c|}
\hline Impacto positivo & \multicolumn{1}{|c|}{$\begin{array}{c}\text { Classificação } \\
\text { do impacto }\end{array}$} & $\begin{array}{c}\text { Classificação da } \\
\text { potencialidade }\end{array}$ & $\begin{array}{c}\text { Classificação } \\
\text { final do impacto }\end{array}$ \\
\hline $\begin{array}{l}\text { Criação de oportunidade de trabalho } \\
\text { derivada da animação econômica }\end{array}$ & Moderadamente alto & Alto & Moderadamente alto \\
\hline $\begin{array}{l}\text { Criação de oportunidade de trabalho } \\
\text { durante a construção das UHEs }\end{array}$ & Baixo & Alto & Médio \\
\hline $\begin{array}{l}\text { Aumento da arrecadação municipal } \\
\text { Expansão do valor adicionado }\end{array}$ & Moderadamente alto & Alto & Moderadamente alto \\
\hline
\end{tabular}

UHEs: usinas hidrelétricas.

Fonte: adaptado de EPE (2007). 
a época da construção da UHE São Salvador. O mesmo fenômeno ocorreu em São Salvador do Tocantins, que passou de 2.843 moradores em 2006 para 3.136 em 2009; e em Palmeirópolis, que apresentava 5.407 habitantes em 2006 e passou a 8.492, em 2009. Nesses municípios, viu-se declínio populacional nos três anos subsequentes. Já no município de Peixe, houve aumento populacional gradativo de 2006 a 2015.

A Tabela 2 mostra os dados relativos ao saldo de emprego nesses municípios. Essa informação representa o número de vagas ofertadas excluindo as demissões ocorridas no período, ou seja, contratação menos demissão.

Os números indicam saldo de emprego declinante, não correspondendo às previsões de médio prazo da AAI. O efeito positivo de geração de empregos foi apenas a curto prazo, com quantidade limitada de vagas, e especificamente durante as obras, ocasionando um déficit impactante nos municípios-sede dos empreendimentos. Sob efeito do término da implantação da UHE Peixe Angical, Peixe apresentou saldo negativo de
1.447 empregos em 2006. Fato semelhante ocorreu em 2008 com o término da UHE São Salvador no município da obra, São Salvador do Tocantins. No cenário de 2015, o saldo de empregos dos municípios correspondeu a apenas 15 empregos em Palmeirópolis, um em Paranã, 40 em Peixe e um em São Salvador do Tocantins.

Comparando o cenário previsto na AAl, a curto e médio prazos (Quadros 1 e 2), com o saldo de empregos (Tabela 2), observa-se que o que foi classificado como moderadamente alto em termos de criação de oportunidades de trabalho derivada da animação econômica, não correspondeu com o saldo de empregos depois da entrada em operação dos empreendimentos.

Em caráter complementar, analisou-se também a criação de empresas abertas nesses municípios a partir da implementação e da operação das UHEs, buscando ampliar a possibilidade de investigação no que diz respeito à criação de oportunidade de trabalho derivada da animação econômica. A Tabela 3 apresenta o número de microempresas e microempreendedores individuais registrados no período.

Tabela 1 - População dos municípios no período de 2006 a 2015.

\begin{tabular}{|l|c|c|c|c|c|c|c|c|c|c|}
\hline Município & 2006 & 2007 & 2008 & 2009 & 2010 & 2011 & 2012 & 2013 & 2014 & 2015 \\
\hline Palmeirópolis & 5.504 & 8.120 & 8.366 & 8.492 & 7.342 & 7.360 & 7.380 & 7.600 & 7.623 & 7.645 \\
\hline Paranã & 10.009 & 10.491 & 10.794 & 10.824 & 10.335 & 10.333 & 10.327 & 10.585 & 10.579 & 10.573 \\
\hline Peixe & 8.677 & 8.750 & 9.002 & 9.018 & 10.389 & 10.509 & 10.629 & 11.075 & 11.209 & 11.340 \\
\hline $\begin{array}{l}\text { São Salvador } \\
\text { do Tocantins }\end{array}$ & 2.843 & 3.012 & 3.102 & 3.136 & 2.910 & 2.924 & 2.936 & 3.030 & 3.044 & 3.058 \\
\hline
\end{tabular}

Fonte: Governo do Tocantins (2019).

Tabela 2 - Saldo de empregos dos municípios no período de 2006 a 2015.

\begin{tabular}{|l|c|c|c|c|c|c|c|c|c|c|}
\hline Município & 2006 & 2007 & 2008 & 2009 & 2010 & 2011 & 2012 & 2013 & 2014 & 2015 \\
\hline Palmeirópolis & 817 & 955 & 28 & 34 & 33 & -2 & 34 & -2 & 0 & 15 \\
\hline Paranã & -4 & 0 & -6 & 5 & 17 & 15 & 43 & 66 & 38 & 1 \\
\hline Peixe & -1.447 & 2 & -84 & 68 & -66 & 21 & 68 & 36 & -3 & 40 \\
\hline $\begin{array}{l}\text { São Salvador } \\
\text { do Tocantins }\end{array}$ & 522 & -6 & -1.501 & -421 & -121 & -18 & -3 & 11 & 0 & 1 \\
\hline
\end{tabular}

Fonte: Governo do Tocantins (2019). 
Verifica-se acréscimo dos registros de empresas. Entretanto, é necessário destacar que a Lei Geral da Micro e Pequena Empresa - Lei Complementar no 123/2006 - e sua subsequente complementação - Lei Complementar no 128/2008 (BRASIL, 2006; 2008b) -, com o apoio do Sebrae, fizeram um trabalho de regularização dos microempreendedores nos municípios. Dessa forma, aqueles prestadores de serviços que viviam na informalidade passaram a ser registrados como empreendedores individuais. Isso explica novos registros de negócios formais nas localidades. Não necessariamente se podem atribuir tais resultados à chegada das UHEs. Sabe-se ainda que vários empreendedores, mesmo quando finalizam suas atividades, não encerram imediatamente o registro da empresa nos órgãos oficiais.
Diante disso, o número de empresas abertas não necessariamente condiz com a criação de postos de trabalho, uma vez que, tratando-se de microempreendedor, cada empresa pode ter apenas um funcionário (o proprietário). Essa situação pode ser analisada a partir da Tabela 2, que demonstra claramente o saldo de empregos declinante, não confirmando a previsão da AAl, que classificou como moderadamente alta a oportunidade de trabalho.

Para análise do disposto na AAI relacionado ao aumento da arrecadação municipal, verificaram-se o ICMS e o comportamento desse indicador econômico. A Tabela 4 mostra a arrecadação dos quatro municípios durante o período.

Tabela 3 - Empresas criadas nos municípios no período de 2007* a 2015.

\begin{tabular}{|l|c|c|c|c|c|c|c|c|c|}
\hline Município & 2007 & 2008 & 2009 & 2010 & 2011 & 2012 & 2013 & 2014 & 2015 \\
\hline Palmeirópolis & 113 & 125 & 139 & 208 & 239 & 287 & 309 & 352 & 373 \\
\hline Paranã & 62 & 71 & 77 & 120 & 151 & 201 & 235 & 276 & 284 \\
\hline Peixe & 66 & 76 & 80 & 145 & 187 & 228 & 291 & 345 & 383 \\
\hline $\begin{array}{l}\text { São Salvador } \\
\text { do Tocantins }\end{array}$ & 25 & 28 & 30 & 59 & 79 & 97 & 97 & 106 & 106 \\
\hline
\end{tabular}

* O Serviço Brasileiro de Apoio às Micro e Pequenas Empresas (Sebrae) não realizava o levantamento por município até o ano de 2006; por isso, nessa tabela, excluímos o ano de 2006 e analisou-se a partir de 2007.

Fonte: Sebrae (2019).

Tabela 4 - Imposto sobre Circulação de Mercadoria e Serviços dos municípios no período de 2006 a 2015 (em reais).

\begin{tabular}{|l|c|c|c|c|}
\hline Ano & Palmeirópolis & Paranã & Peixe & São Salvador \\
\hline 2006 & $859.567,43$ & $558.034,77$ & $1.679 .029,22$ & $267.656,69$ \\
\hline 2007 & $906.841,33$ & $650.636,44$ & $1.832 .768,99$ & $351.171,85$ \\
\hline 2008 & $963.457,81$ & $704.804,57$ & $4.604 .635,74$ & $448.042,50$ \\
\hline 2009 & $894.819,44$ & $827.518,31$ & $11.167 .883,84$ & $497.667,46$ \\
\hline 2010 & $1.070 .984,98$ & $1.055 .788,90$ & $15.363 .955,53$ & $628.832,88$ \\
\hline 2011 & $1.319 .598,16$ & $3.643 .573,00$ & $14.970 .035,06$ & $594.881,49$ \\
\hline 2012 & $1.386 .540,95$ & $7.223 .335,54$ & $16.547 .367,16$ & $596.737,52$ \\
\hline 2013 & $1.592 .298,39$ & $9.112 .195,22$ & $17.573 .763,06$ & $699.064,21$ \\
\hline 2014 & $1.807 .288,42$ & $10.103 .740,00$ & $18.079 .440,80$ & $823.645,69$ \\
\hline 2015 & $2.140 .156,16$ & $10.342 .906,67$ & $18.375 .682,17$ & $962.184,61$ \\
\hline
\end{tabular}

Fonte: Governo do Tocantins (2019). 
Constata-se que a arrecadação foi crescente durante os anos subsequentes à construção das usinas, confirmando as previsões da AAI de aumento da arrecadação tanto a curto como a médio prazo. Sobretudo, os municípios-sedes dos empreendimentos tiveram um salto maior, pois recebem pela geração de energia.

Em relação ao PIB, a Tabela 5 demonstra a atividade econômica da região, ou seja, a produção de bens e serviços finais.

Analisando a Tabela 5, observa-se aumento gradativo do PIB nos municípios de Palmeirópolis, Paranã e Peixe. No entanto, não se pode atribuir esse resultado apenas à implantação das hidrelétricas, uma vez que outros fatores econômicos podem ter impulsionado esse indicador, a exemplo da construção de rodovias, contemplando o projeto de ampliação da malha viária no Tocantins e da agropecuária em expansão no estado (GOVERNO DO TOCANTINS, 2012). Já em São Salvador do Tocantins ocorreu o processo oposto. O PIB teve significativo aumento no ano de 2007 , em plena construção da UHE São Salvador, em relação a 2006, mas a partir de 2008 sofreu queda brusca, chegando em 2015 com menos de 50\% da posição inicial em 2006.

De forma a contribuir com a avaliação de impactos socioeconômicos, buscou-se analisar também dados socioeconômicos que possibilitam uma visão panorâmica do município antes e depois no processo pós-barragem. A Tabela 6 apresenta o IDH dos municípios nos anos 2000 (antes das UHEs) e 2010 (após as UHEs).

Tabela 5 - Produto interno bruto dos municípios no período de 2006 a 2015 (em reais).

\begin{tabular}{|l|c|c|c|c|}
\hline Ano & Palmeirópolis & Paranã & Peixe & São Salvador \\
\hline 2006 & 31.532 & 34.316 & 120.957 & 68.129 \\
\hline 2007 & 43.291 & 41.222 & 308.586 & 108.549 \\
\hline 2008 & 54.982 & 49.489 & 362.103 & 45.322 \\
\hline 2009 & 58.499 & 88.611 & 349.530 & 31.726 \\
\hline 2010 & 60.013 & 199.268 & 421.892 & 31.646 \\
\hline 2011 & 66.062 & 199.032 & 445.361 & 20.839 \\
\hline 2012 & 72.530 & 301.799 & 506.273 & 22.803 \\
\hline 2013 & 85.374 & 255.093 & 511.246 & 25.810 \\
\hline 2014 & 92.595 & 172.785 & 389.475 & 26.710 \\
\hline 2015 & 104.183 & 195.055 & 545.343 & 28.872 \\
\hline
\end{tabular}

Fonte: Governo do Tocantins (2019).

Tabela 6 - Índice de Desenvolvimento Humano dos anos 2000 e 2010.

\begin{tabular}{|l|c|c|}
\hline Municípios & $\mathbf{2 0 0 0}$ & $\mathbf{2 0 1 0}$ \\
\hline Palmeirópolis & 0,545 & 0,673 \\
\hline Paranã & 0,334 & 0,595 \\
\hline Peixe & 0,482 & 0,674 \\
\hline São Salvador do Tocantins & 0,419 & 0,605 \\
\hline
\end{tabular}

Fonte: IBGE (2019). 
Conforme os dados, os municípios obtiveram relativa evolução, comparando-se o início ao final da década. Peixe e São Salvador do Tocantins ultrapassaram o patamar de muito baixo desenvolvimento para se enquadrarem na condição de médio desenvolvimento humano, enquanto Paranã avançou de muito baixo para baixo desenvolvimento, de acordo com a classificação do IDH. Todavia, a melhoria desse indicador foi uma tendência em função da criação do estado do Tocantins em 1988, que impulsionou a presença do Estado, com bens e serviços nos municípios do antigo norte goiano. De modo geral, todos os municípios tocantinenses tiveram aumento de indicadores sociais no período que corresponde de 1991 a 2010. A progressão do IDH-M no Tocantins foi de: $1991=0,369 ; 2000=0,525$; e $2010=0,699$, uma evolução de muito baixo para médio desenvolvimento humano (GOVERNO DO TOCANTINS, 2017).

Esse efeito também se reflete na renda per capita dos municípios pesquisados, que teve melhoria de 2000 para 2010, como mostra a Tabela 7.

Apesar do aumento da renda, quando em consulta ao IBGE, os indicadores de rendimento nominal mensal per capita revelam valores críticos. Os municípios chegam ao ano de 2010 com praticamente metade de suas populações sobrevivendo com meio salário mínimo: Palmeirópolis (43\%), Paranã (49,6\%), Peixe $(41,4 \%)$ e São Salvador (48,9\%) (IBGE, 2019). Esses dados ratificam a Tabela 2, que exibe saldo de empregos em declínio após a finalização das construções das UHEs. Dessa forma, não corresponde ao cenário de aumento da renda previsto na AAI.

Seguindo a análise socioeconômica, verifica-se na Tabela 8 que a taxa de analfabetismo também teve redução, porém muito pequena se comparada às tendências de desenvolvimento dos municípios, tanto em função da criação do Tocantins quanto sob a perspectiva da AAI.

Destaca-se, por exemplo, o município de Paranã, com uma população de pouco mais de 10 mil habitantes, apresentando $25,9 \%$ de analfabetismo, um índice considerável para uma localidade que deveria ter sido beneficiada pela instalação de duas UHEs.

Por fim, na dimensão saúde, é importante discutir a taxa de mortalidade infantil, apresentada na Tabela 9. Nota-se variação de óbitos nos quatro municípios. Em alguns deles, na contramão da proposta da AAl, a

Tabela 7 - Renda per capita dos municípios nos anos 2000 e 2010 (em reais).

\begin{tabular}{|l|c|c|}
\hline Municípios & $\mathbf{2 0 0 0}$ & $\mathbf{2 0 1 0}$ \\
\hline Palmeirópolis & 339,21 & 463,45 \\
\hline Paranã & 175,47 & 311,37 \\
\hline Peixe & 244,10 & 547,90 \\
\hline São Salvador do Tocantins & 157,46 & 318,39 \\
\hline
\end{tabular}

Fonte: IBGE (2019).

Tabela 8 - Taxa de analfabetismo da população de 15 anos ou mais, no período de 2000 e 2010 (em \%).

\begin{tabular}{|l|c|c|}
\hline Municípios & $\mathbf{2 0 0 0}$ & $\mathbf{2 0 1 0}$ \\
\hline Palmeirópolis & 19 & 13,3 \\
\hline Paranã & 31 & 25,9 \\
\hline Peixe & 23,3 & 16,5 \\
\hline São Salvador do Tocantins & 27,3 & 19 \\
\hline
\end{tabular}

Fonte: Atlas Brasil (2013). 
taxa foi crescente ao longo dos anos. É o caso de Palmeirópolis, que passa de $9,2 \%$, em 2006 , para $18,69 \%$, em 2010 , e para $30,77 \%$, em 2013 , reduzindo apenas em 2014 para 13,07\%. O único município que obteve redução significativa da taxa foi Peixe, que diminuiu de 15,6\%, em 2006, para 7,75\%, em 2014. Atribui-se essa redução ao sistema de saúde de Peixe, mais estruturado em relação aos demais municípios pesquisados, pois o efeito da compensação da UHE Peixe Angical proporcionou a ampliação do número de leitos e a reforma do centro cirúrgico do Hospital Municipal de Peixe.

Apesar de não ter registrado óbitos no período de 2007 a 2012, São Salvador do Tocantins apresentou acentuada taxa de mortalidade infantil, com $35,71 \%$, em 2013, e 27,78\%, em 2014, o dobro de mortes por mil nascidos vivos da média do Brasil, que em 2014 foi de 14,40 óbitos por mil nascidos vivos. Ressalta-se que São Salvador do Tocantins é sede de UHE e deveria ter melhorado esse indicador de saúde.

A pesquisa demonstrou que o cenário de desenvolvimento socioeconômico preconizado pela AAl em função das UHEs para Palmeirópolis, Paranã, Peixe e São Salvador do Tocantins atendeu parcialmente às expectativas. As previsões consolidaram-se no que se refere à arrecadação, com o incremento de recursos financeiros nos quatro municípios. No entanto, as expectativas de criação de vagas de trabalho, geração de emprego, aumento da renda da população e melhoria de indicadores sociais não se concretizaram. Esse resultado corrobora com estudo de Gomes et al. (2017), que evidenciou que os recursos financeiros advindos da implantação dos empreendimentos não necessariamente se traduzem em desenvolvimento local e avanços sociais.
Nesse contexto, Assunção, Szerman e Costa (2016), em estudo sobre os efeitos locais de hidrelétricas no Brasil, concluíram que a economia dos municípios só é impactada positivamente nos primeiros anos dos empreendimentos, ou seja, no curto prazo. O PIB per capita dos 82 municípios atingidos por hidrelétricas estudados por esses autores apresentou, de forma geral, um crescimento de 7 a 10\%, e o emprego formal aumentou entre 10 e $40 \%$ no período da construção da barragem. No entanto, após cinco anos do início da construção da UHE, não foram encontrados efeitos na taxa de crescimento do PIB municipal, no PIB per capita, no número de empresas locais e nem na população dos municípios. Além disso, os pesquisadores evidenciaram que as construções das dez UHEs analisadas causaram aumento de 279 mil hectares de área desmatada em relação ao que ocorreria caso elas não tivessem sido construídas, ou seja, o impacto ambiental pode ter sido maior que os benefícios alcançados (ASSUNÇÃO; SZERMAN; COSTA, 2016).

Benincá (2011) ressalta que é praticamente impossível quantificar e qualificar os impactos totais que incidem nas pessoas das localidades e o conjunto da biodiversidade. Os custos sociais e ambientais da hidrelétrica continuam após a implementação, tornando-se fonte de controvérsias em vista do que foi anunciado. Em nome do desenvolvimento, inúmeras famílias são deslocadas e atingidas largamente. E o desenvolvimento, na maioria dos casos, pode não ocorrer. Portanto, ainda que a AAl se proponha a traçar os cenários a curto, médio e longo prazos, respaldados em estudos de viabilidade técnica, esses podem não corresponder às expectativas, já que fatores sociais, econômicos e culturais, bem como a gestão municipal, podem alterar os resultados visualizados.

Tabela 9 - Taxa de mortalidade infantil no período de 2006 a 2014 (percentual por mil nascidos vivos).

\begin{tabular}{|l|c|c|c|c|c|c|c|c|c|}
\hline Municípios & 2006 & 2007 & 2008 & 2009 & 2010 & 2011 & 2012 & 2013 & 2014 \\
\hline Palmeirópolis & 9,2 & 16,8 & 6,7 & 9,8 & 18,69 & 13,16 & - & 30,77 & 13,07 \\
\hline Paranã & 5,0 & 9,9 & 9,0 & 12,5 & 11,63 & 35,09 & 18,63 & 14,71 & 14,49 \\
\hline Peixe & 15,6 & - & 13,7 & 19,87 & 11,98 & 12,99 & 26,09 & 8,13 & 7,75 \\
\hline $\begin{array}{l}\text { São Salvador } \\
\text { do Tocantins }\end{array}$ & 28,6 & - & - & - & - & - & - & 35,71 & 27,78 \\
\hline
\end{tabular}

Fonte: DATASUS (BRASIL, 2019); IBGE (2019). 


\section{CONSIDERAÇÕES FINAIS}

Após a comparação dos dados socioeconômicos dos municípios de Palmeirópolis, Paranã, Peixe e São Salvador do Tocantins com o cenário da AAI dos Aproveitamentos Hidrelétricos da Bacia do Rio Tocantins, percebeu-se que as previsões do estudo técnico no espaço temporal a médio prazo (até 2015) se concretizaram parcialmente. Houve, em alguns casos, o aumento de indicadores socioeconômicos nas localidades pesquisadas, sobretudo em relação ao ICMS e ao PIB. Entretanto, não se pode atribuir essa melhoria unicamente à chegada das UHEs, uma vez que os municípios tocantinenses, de modo geral, apresentam tendência de crescimento, induzidos por políticas públicas após a criação do estado do Tocantins.

A UHE Peixe Angical e a UHE São Salvador contribuíram com o aumento da arrecadação nas localidades pesquisadas. Todavia, esses recursos não se traduziram em melhoria das condições de vida da população local. Um exemplo demonstrado é a taxa de mortalidade infantil, que manteve índices elevados no cenário a médio prazo, em algumas situações acima da média nacional. Esses problemas são indicativos de que déficits socioe- conômicos podem ter sido deixados para a gestão municipal resolver após o desmonte das obras das UHEs.

Admite-se que a AAl é um instrumento importante para o planejamento de investimentos nas bacias hidrográficas. Porém, suas técnicas de avaliação devem ser aprimoradas para permitir melhor mensuração das fragilidades socioeconômicas locais, facilitando a mediação para a negociação dos conflitos entre as políticas de meio ambiente e energia.

As construções e as desconstruções de cenários futuros devem contar com a participação ativa de todos os atores envolvidos. A sociedade deve participar expressando os níveis de sentimentos, dúvidas, angústia e desespero de suas realidades e expectativas em relação ao projeto (obra), de modo a se envolver no processo de tomada de decisões, além da participação e da vigilância ativa do cumprimento das medidas compensatórias e mitigatórias e da aplicação dos recursos financeiros municipais que devem ser investidos em projetos e ações visando à melhoria da qualidade de vida local.

\section{REFERÊNCIAS}

AMNESTY INTERNATIONAL. Le point de non-retour: Les droits des peuples autochtones du Canada manacés par le barrage du site C. Londres: Amnesty International, 2016.

ASSUNÇÃO, J.; SZERMAN, D.; COSTA, F. Estudo: Efeitos locais de hidrelétricas no Brasil. Climate Policy Iniciative, 2016.

ATLAS BRASIL. Atlas do Desenvolvimento Humano no Brasil. Plataforma de Consulta. PNUD/IPEA/Fundação João Pinheiro, 2013. Disponível em: <http://atlasbrasil.org.br/2013/pt/consulta/>. Acesso em: abr. 2019.

BARDIN, L. Análise de Conteúdo. São Paulo: Edições 70, 2011.

BENINCÁ, D. Energia \& cidadania: a luta dos atingidos por barragens. São Paulo: Cortez, 2011.

BORTOLETO, E. M. A implantação de grandes hidrelétricas: desenvolvimento, discurso e impactos. Geografares, n. 2, p. 53-62, 2001. https://doi.org/10.7147/GEO2.1140

BRASIL. Constituição da República Federativa do Brasil: texto constitucional promulgado em 5 de outubro de 1988, com as alterações adotadas pelas Emendas Constitucionais no 1/92 a 55/2007 e pelas Emendas Constitucionais de Revisão no 1 a 6/94. Brasília: Senado Federal, Subsecretaria de Edições Técnicas, 2008a.

. Datasus. Ministério da Saúde. Cadernos de Informações de Saúde do Tocantins. Disponível em: <http://tabnet. datasus.gov.br/tabdata/cadernos/to.htm>. Acesso em: maio 2019. 
. Lei Complementar no 128, de 19 de dezembro de 2008. Casa Civil, 2008b. Disponível em: <http://www.planalto. gov.br/ccivil_03/Leis/LCP/Lcp128.htm>. Acesso em: jul. 2019.

. Lei Geral da Micro e Pequena Empresa, no 123 de 14 de dezembro de 2006. Casa Civil, 2006. Disponível em: <http://www.planalto.gov.br/ccivil_03/Leis/LCP/Lcp123.htm>. Acesso em: jul. 2019.

. Plano Decenal de Expansão de Energia 2024. Brasília: Ministério de Minas e Energia, Empresa de Pesquisa Energética, 2015.

. Resolução Conama no 001, de 23 de janeiro de 1986. Diário Oficial da União, 1986. Disponível em: <http:// www.mma.gov.br/port/conama/res/res86/res0186.html>. Acesso em: maio 2019.

CASTRO, F.; HOGENBOOM, B.; BAUD, M. Governança ambiental na América Latina. Ciudad Autónoma de Buenos Aires: CLACSO; Amsterdã: Engov, 2015.

EMPRESA DE PESQUISA ENERGÉTICA (EPE). Avaliação Ambiental dos Aproveitamentos Hidrelétricos da Bacia do Rio Tocantins. Avaliação Ambiental Distribuída e Conflitos. Relatório Final. Brasília: EPE, 2007.

FAINGUELERNT, M. B. A trajetória histórica do processo de licenciamento ambiental da usina hidrelétrica de Belo Monte. Ambiente e Sociedade, São Paulo, v. 19, n. 2, p. 245-264, abr.-jun. 2016. http://dx.doi.org/10.1590/18094422ASOC0259R1V1922016

FEARNSIDE, P. M. Hidrelétricas na Amazônia: Impactos ambientais e sociais na tomada de decisões sobre grandes obras. Manaus: Editora INPA, 2015. v. 2.

GOMES, C.S.; ROQUETTI, D.R.; PULICE, S.M.P.; MORETTO, E.M. Usinas Hidrelétricas e o Desenvolvimento Municipal: O Caso das Usinas Hidrelétricas do Complexo Pelotas-Uruguai. Gestão Ambiental e Sustentabilidade, v. 6, n. 2, maio/ ago. 2017. http://dx.doi.org/10.5585/geas.v6i2.931

GOVERNO DO TOCANTINS. Atlas do Tocantins: Subsídios ao planejamento da gestão Territorial. Palmas: Secretaria do Planejamento e da Modernização da Gestão Pública, 2012.

. Departamento de Planejamento e Estatística do Tocantins. Palmas: Secretaria da Fazenda e Planejamento, 2019.

. Indicadores Socioeconômicos do Estado do Tocantins. Palmas: Secretaria do Planejamento e Orçamento, 2017.

INSTITUTO BRASILEIRO DE GEOGRAFIA E ESTATÍ́STICA (IBGE). Censo 2010. Instituto Brasileiro de Geografia e Estatística. Disponível em: <http://censo2010.ibge.gov.br/>. Acesso em: abr. 2017.

. Cidades. IBGE. Disponível em: <https://cidades.ibge.gov.br/>. Acesso em: abr. 2019.

LITTLE, P. E. Mega-development Projects in Amazonia: A geopolitical and socioenvironmental primer. Lima: Derechos, Ambiente y Recursos Naturales, 2014.

PIAGENTINI, P. M.; FAVARETO, A. da S. Instituições para regulação ambiental: o processo de licenciamento ambiental em quatro países produtores de hidroeletricidade. Desenvolvimento e Meio Ambiente, v. 30, jul. 2014. http://dx.doi. org/10.5380/dma.v30i0.33029

ROCHA, H. J. da. Hidrelétricas e Desenvolvimento Regional: Elementos para Análise. In: ENCONTRO INTERNACIONAL CIÊNCIAS SOCIAIS E BARRAGENS, 4., 2016. Anais... Chapecó, 2016.

ROCHA, H. J. J.; PASE, H. L. O Conflito Social e Político nas Hidrelétricas da Bacia do Uruguai. Revista Brasileira de Ciências Sociais, v. 30, n. 88, p. 99-113, jun. 2015. http://dx.doi.org/10.17666/308899-113/2015 
SAIFI, S. E; DAGNINO, R. S. Grandes projetos de desenvolvimento e implicações sobre as populações locais: o caso da usina de Belo Monte e a população de Altamira, Pará. In: CIRCUITO DE DEBATES ACADÊMICOS, 1., 2011, Code. Anais... 2011.

SERVIÇO BRASILEIRO DE APOIO A MICRO E PEQUENAS EMPRESAS (SEBRAE). Departamento de Estatística Empresarial. Palmas: Sebrae, 2019.

TUCCI, C. E. M.; MENDES, C. A. Avaliação Ambiental Integrada de Bacia Hidrográfica. Brasília: Ministério do Meio Ambiente, 2006.

VAINER, C. B.; ARAÚJO, F. G. B. Grandes projetos hidrelétricos e o desenvolvimento regional. Rio de Janeiro: Centro Ecumênico de Documentação e Informação, 1992.

WESTIN, F. F.; SANTOS, M. A.; MARTINS, I. D. Hydropower expansion and analysis of the use of strategic and integrated environmental assessment tools in Brazil. Renewable and Sustainable Energy Reviews, n. 37, 2014. http://dx.doi. org/10.1016/j.rser.2014.04.071 